\title{
Influence of Geometry and Boundary Conditions in Area of Cohesion between Materials on the Reflection of an Ultrasonic Beam. Part 1. Theoretical Research
}

\author{
A.R. Bayev ${ }^{1}$, A.L. Mayorov ${ }^{1}$, N.V. Levkovich ${ }^{2}$, D.V. Shavlovskiy ${ }^{3}$, M.V. Asadchaya ${ }^{1}$ \\ ${ }^{1}$ Institute of Applied Physics of the National Academy of Science of Belarus, \\ Akademicheskaya str., 16, Minsk 220072, Belarus \\ ${ }^{2}$ Belarusian State Univercity, \\ Nezavisimosty Ave., 4, Minsk 220030, Belarus \\ ${ }^{3}$ Beltopgas SPA, \\ Vera Horuzhei str., 3, Minsk 220005, Belarus
}

Received 08.04.2021

Accepted for publication 02.06.2021

\begin{abstract}
The improvement of efficiency, reliability and productivity of ultrasonic testing of objects with cohesion between materials connected by welding, soldering, gluing, etc. is 'an important problem of the modern production technologies. The purpose of the paper is to determine in 3D space the conditions for increasing the sensitivity and reliability of the flaw detection in the cohesion zone between materials when the form of defect interface can be different.

In the first part of the theoretical study the features of the formation of the acoustic fields of ultrasonic waves scattered from solid's interface when spot of an acoustic beam crosses the boundary of the defective region in the shape of an ellipse or a long strip have been investigated. In this case, the boundary conditions in the defect area change discretely or linearly.

It was suggested to use a phase shift between reflected waves from the defect and defect-free interfaces as the more informative parameter depending on the cohesion between materials. There is shown that there are conditions to achieve sufficiently high sensitivity detection of interface defects when the scattered waves receiving are to be at angles outside the main directivity lobe of the scattering field pattern. The evolution features of the scattering field structure which are needed for the development of the method of evaluation the cohesion of materials have been got.
\end{abstract}

Keywords: ultrasonic waves, diagram directivity (DD), reflection, wave scattering.

DOI: $10.21122 / 2220-9506-2021-12-2-124-132$

\begin{tabular}{|c|c|}
\hline $\begin{array}{l}\text { Адрес для переписки: } \\
\text { Баев А.Р. } \\
\text { Ин-т прикладной физики Национальной академии наук Беларуси, } \\
\text { ул. Академическая, 16, г. Минск 220072, Беларусь } \\
\text { e-mail: baеv@iaph.bas-net.by }\end{array}$ & $\begin{array}{l}\text { Address for correspondence: } \\
\text { Bayev A.R. } \\
\text { Institute of Applied Physics of the National Academy } \\
\text { of Science of Belarus, } \\
\text { Akademicheskaya str., 16, Minsk 220072, Belarus } \\
\text { e-mail: baev@iaph.bas-net.by }\end{array}$ \\
\hline Для цитирования: & For citation: \\
\hline $\begin{array}{l}\text { A.R. Bayev, A.L. Mayorov, N.V. Levkovich, D.V. Shavlovskiy, } \\
\text { M.V. Asadchaya. }\end{array}$ & $\begin{array}{l}\text { A.R. Bayev, A.L. Mayorov, N.V. Levkovich, D.V. Shavlovskiy, } \\
\text { M.V. Asadchaya. }\end{array}$ \\
\hline Influence of Geometry and Boundary Conditions in Area of Cohesion & Influence of Geometry and Boundary Conditions in Area of Cohesion \\
\hline between Materials on the Reflection of an Ultrasonic Beam. & between Materials on the Reflection of an Ultrasonic Beam. \\
\hline Part 1. Theoretical Research. & Part 1. Theoretical Research. \\
\hline Приборы и методы измерений. & Devices and Methods of Measurements. \\
\hline 2021. - T. 12, № 2. - C. 124-132. & 2021, vol. 12, no. 2, pp. $124-132$. \\
\hline DOI: $10.21122 / 2220-9506-2021-12-2-124-132$ & DOI: $10.21122 / 2220-9506-2021-12-2-124-132$ \\
\hline
\end{tabular}




\title{
Влияние геометрии и граничных условий в области сцепления материалов на рассеяние ультразвуковых волн. Ч. 1. Теоретическое моделирование
}

\author{
А.Р. Баев ${ }^{1}$, А.Л. Майоров ${ }^{1}$, Н.В. Левкович ${ }^{2}$, Д.В. Шавловский ${ }^{3}$, М.В. Асадчая ${ }^{1}$ \\ ${ }^{1}$ Институт прикладной физики Национальной академии наук Беларуси, \\ ул. Академическая, 16, г. Минск 220072, Беларусь \\ ${ }^{2}$ Белорусский государственный университет, \\ пр-m Независимости, 4, г. Минск 220030, Беларусь \\ ${ }^{3}$ ГПО по топливу и газификации «Белтопгаз», \\ ул. В. Хоружей, 3, г. Минск 220005, Беларусь \\ Поступила 08.04.2021 \\ Принята к печати 02.06.2021
}

Повышение эффективности, надёжности и производительности ультразвукового контроля соединения материалов сваркой, пайкой, склеиванием и др. является важной народнохозяйственной задачей. Цель работы состояла в установлении условий повышения чувствительности и достоверности обнаружения дефектов сцепления материалов на основе моделирования полей ультразвуковых мод, рассеянных дефектами разной геометрии.

Впервые в максиальном приближении выполнен расчёт и анализ полей рассеяния ультразвуковых волн при перемещении пятна акустического луча в виде эллипса или длинной полосы относительно дефектной области с дискретными и плавно изменяющимися в ней граничными условиями. Для характеристики последних с точки зрения взаимодействия упругой волны с границей сред предложено использовать преимущественно фазовый сдвиг $\theta$ между волнами, рассеянными от дефектной и бездефектной границы, существенно сказывающийся на изменении параметров результирующего поля рассеяния в его периферийной зоне. Т. е., $\theta$ является важным параметром, характеризующим степень сцепления материалов и оказывающим превалирующее влияние на чувствительность предлагаемого метода обнаружения слабо выявляемых дефектов.

Установлены особенности эволюции структуры полей рассеяния, являющиеся первичными для разработки методик контроля сцепления материалов предложенным методом. При достаточно малых значениях угла приёма ультразвуковых колебаний в меридиональной плоскости максимум чувствительности измерений достигается в динамическом режиме и приёме рассеянных волн под азимутальными углами, соответствующими 1-му экстремуму диаграммы направленности поля рассеяния опорного акустического луча.

Ключевые слова: диаграмма направленности, неразъёмное соединение, рассеяние упругих волн.

DOI: $10.21122 / 2220-9506-2021-12-2-124-132$

\begin{tabular}{ll}
\hline Адрес для переписки: & Address for correspondence: \\
Баев А.P. & Bayev A.R. \\
Ин-т прикладной физики Национальной академии наук Беларуси, & $\begin{array}{l}\text { Institute of Applied Physics of the National Academy } \\
\text { ул. Академическая, 16, г. Минск 220072, Беларусь }\end{array}$ \\
e-mail: baеv@iaph.bas-net.by & $\begin{array}{l}\text { Akademicheskaya str., 16, Minsk 220072, Belarus } \\
\text { e-mail: baev@iaph.bas-net.by }\end{array}$ \\
\hline Для цитирования: & For citation: \\
$\begin{array}{l}\text { A.R. Bayev, A.L. Mayorov, N.V. Levkovich, D.V. Shavlovskiy, } \\
\text { M.V. Asadchaya. }\end{array}$ & A.R. Bayev, A.L. Mayorov, N.V. Levkovich, D.V. Shavlovskiy, \\
Influence of Geometry and Boundary Conditions in Area of Cohesion & M.V. Asadchaya. \\
between Materials on the Reflection of an Ultrasonic Beam. & Influence of Geometry and Boundary Conditions in Area of Cohesion \\
Part 1. Theoretical Research. & between Materials on the Reflection of an Ultrasonic Beam. \\
Приборы и методы измерений. & Part 1. Theoretical Research. \\
2021.- T. 12, № 2. - C. 124-132. & Devices and Methods of Measurements. \\
DOI: 10.21122/2220-9506-2021-12-2-124-132 & 2021, vol. 12, no. 2, pp. 124-132. \\
\hline
\end{tabular}




\section{Introduction}

The development of effective methods and means of ultrasonic testing of permanent joints (metal-tometal, metal-to-nonmetal, nonmetal-to-nonmetal) allowing a reliable and safe functioning of critical technical facilities in heating, construction and operation of gas pipelines, in the chemical industry, at enterprises of the auto-tractor construction, instrument engineering and others is very relevant. At the same time high reliability and sensitivity of testing of weakly detectable by ultrasonic methods defective areas of material joining (for example, material sticking faults) in welding, spraying, brazing, gluing and others, is an important applied task [1].

Traditional methods of ultrasonic testing of fixed assemblies mostly use "direct" amplitude methods consisting in determining of amplitude differences of acoustic signal passed or reflected from a defective $\left(S \subset S_{D}\right)$ and non-defective $\left(S \subset S_{N}\right)$ surfaces of contacting surfaces. For this purpose ultrasonic volume waves probing the object by echoing, echoing, as well as shadowing can be used. On the other hand, quality of adhesion of materials characterized by stress tensor $\left(\sigma_{i k}\right)_{j}$ and displacement value of wave $\left(\xi_{i}\right)$ on contacting surfaces both during manufacturing and operation of the object can be estimated by time variations of surface, plate waves, their amplitude, phase [2-4]. And in $[3,4]$ detection of splits in objects with high attenuation coefficient in polymer composites and in multilayer adhesive structures, where lowfrequency plate mode is used as a probe, and their velocity decreases as a result of diffraction scattering on splits depending on "damage" of the object, are considered. If comfortable measurement conditions are provided, including the condition of the object's contact surface, its geometry, inspection performance requirements and the instrumentation used, interferometric measurement schemes are sufficiently sensitive to assess the quality of material adhesion or coating thickness gauging $[5,6]$.

It should be noted that combined methods realized by using optoacoustic excitation of ultrasonic waves and their receiving by both contact and non-contact methods - are promising in solving the above problems [7, 8]. In particular at pulse-laser action a wide spectrum of waves interacting with a defect area is excited in the object. At the same time the "selectivity" effect allows the detection of poorly detectable defect areas based on the signalresponse spectrum data. Increase of the method's efficiency could be achieved by means of receiving Lamb waves in simple electromagnetic-acoustic way [8], if of course, the object is o a double-layer plate with characteristic thickness $h_{i} \geq \lambda_{L}$, where $\lambda_{L}$ is maximum possible Lamb wave length. It should be noted that by changing the configuration of receiver measuring coil it is possible to search for the elastic modes which are the most sensitive to defects of splitting.

Analysis of the above methods of quality testing of solid state joints shows that their sensitivity is not high enough when using traditional measuring methods, while the use of interferometer, phase-frequency methods and laser technology significantly complicates the conditions of testing. It concerns requirements to geometry of objects, state of their surface, etc. The authors [9] on the basis of deterministic approach in 2D formulation develop the method of detecting weakly detectable defects, when the phase shift between the waves scattered at the defect and defect free boundary magnitude of $\theta=\pi / 4-\pi$. In [10] the ultrasonic scattering fields in three-dimensional space - in different planes of the directional cross section of the ultrasonic scattering field DD, characterized by equatorial $(\psi=0-\pi)$ and azimuthal $(\psi=0-\pi / 2)$ angles are investigated. Moreover, the phase shift between the waves scattered at the same at the defective and defect-free boundaries time is constant and its value varies in the range of $\theta=\pi / 4-\pi$.

The aim of this part of the research is to carry out a theoretical qualitative analysis of the acoustic channel including the formation of reflected fields of ultrasonic waves (UW) from a heterogeneous boundary plane surface $S^{*}=S_{D}+S_{N}$ characterized by different profile of $S_{D}$ boundary and phase shift between the reflected waves and to determine the optimum conditions for their detection and achieve maximum sensitivity.

Note that the informative signal at the receiving ultrasonic probe is formed only when a moving spot of incident beam on the interface intersects defect's boundary or defect is inside the spot. Thus, we have possibility to observe the more substantial changing of the UW side lobes structure. Below the peculiarities of acoustic scattering field formation $\Phi(\varphi, \psi)$ are studied for the case, when the defect surface $S_{D}$ has the form of ellipse with eccentricity $(\varepsilon=a / b=0.3-3)$ and 
area ratio $S_{D 0}=S_{D} / S_{0}=0-0.1$ or as a strip, where $S_{0}$ is the acoustic beam $(\boldsymbol{A B})$ cross-section area of its spot, and the phase shift between the scattered waves changes in the range $\theta=0-\pi$. And this variation is not only discrete, but also linear, which is characteristic for cases of imperfect execution of some joining technologies of materials. The conditions for choosing the optimal scheme of sounding are specified.

\section{Analysis of peculiarities of acoustic channel}

At this stage of development of suggested method of diagnosing state (coupling) of contacting materials, mainly aimed at studying peculiarities of influence of geometry of defect area and its position on formed ultrasonic scattering field. Also important is the problem of detecting such defects when the strength of "seizure" or adhesion of materials in the defective area changes depending on the coordinates $\{x, y\} \subset S_{D}$. I. e. at characteristic angles of incidence of elastic waves on the local zone we should expect changes in phase shift, which is a function of $\theta=\theta\left(\sigma_{i k}, \Re_{i}, C_{1}, C_{2}, \beta\right)$. And this should have some effect on the scattering field under study. Thus the subject of the present studies are peculiarities of DD formation in space of scattering ultrasonic waves when a spot of an acoustic beam with moving relative to the boundary of the defective surface having the form of an ellipse with varied eccentricity $\varepsilon=0.3-3$ or a long strip. In this case the boundary conditions in the area of wave incidence on the defect change discretely or linearly vs. distance from the sport boundary in $x$ direction, where $a$ and $b$ are axes of an ellipse (Figure 1a).

When variant II is implemented, the problem under consideration is represented as a superposition of the fields of the two sources:

$J=J_{1}+J_{2}=A_{0} S_{0} K_{R 0} F_{0}(\psi, \varphi)+$

$A_{0} S_{D}\left[K_{R} F_{D 0}(\psi, \varphi, \theta(x))-K_{R 0} F_{01}(\psi, \varphi)\right]$,

where $A_{0}$ is the amplitude of the acoustic wave incident on the media boundary; $K_{R}$ and $K_{R 0}$ the ultrasonic reflection coefficients from the defectfree and defect bonded area of the materials, respectively; $J$ is the resultant scattering field of the ultrasonic beam incident on the boundary surface with the defect $S_{0}=S_{D}+S_{N}, F_{0}, F_{01}, F_{D 0}$ - are the corresponding normalized integral functions where $F_{01} \equiv F_{0}$ is for the $S \subset S_{D}$.

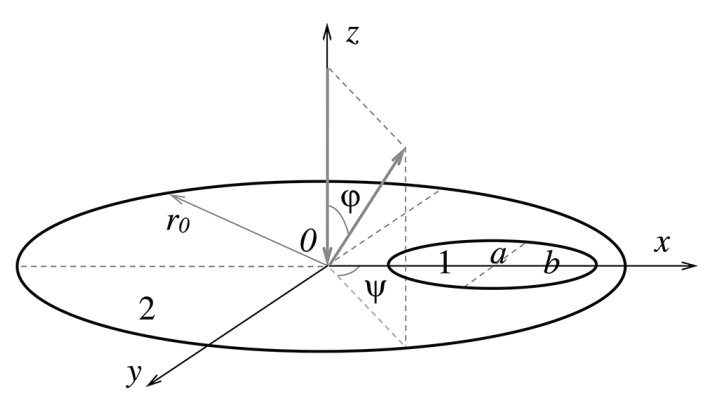

$a$

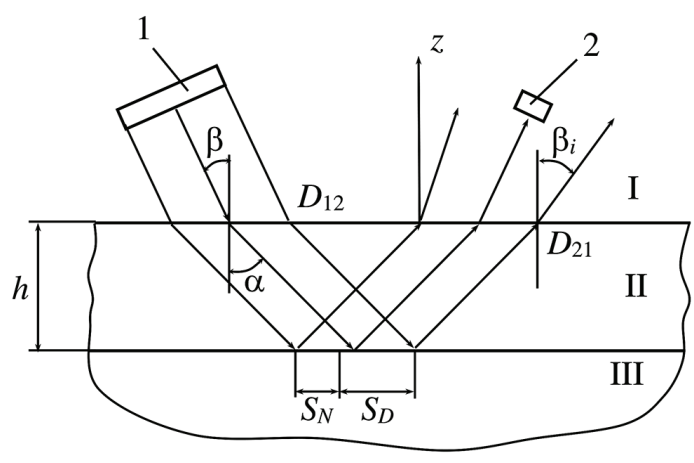

b

Figure 1 - Illustration for the theoretical analysis and calculation of the ultrasonic reflected waves from

For numerical calculation in axial approximation of acoustic fields, obtained at ultrasonic reflection from adhesion surface of materials with defect of different profile integral expressions obtained below were used. This allowed us to reveal specific features of ultrasonic wave (UW) field variations scattered in the presence of a simulated defect area $S_{D}$ of different geometry (Figures 4.2-4.4), including an ellipse, a long strip of width $b<r_{0}$ and a semiinfinite plane. Further by numerical experiment the search of such conditions is carried out, at which the possibility of revealing of defects of incoherence with the minimum possible reflectivity is realized. For this purpose we suggest to use those regions of scattering fields (or angles of UW receiving), where the minimum and maximum of the first order angles of DD $\left(\varphi_{\min 1}, \varphi_{\max 1}\right)$ are located in the equatorial plane of DD section. We suggest to measure values of scattering field amplitudes in its vicinity and to use the amplitude of $A_{\max 1}$ as well as (for comparison) the value of the zero-order maximum $A_{\max 0}$. Dimensionless parameters are used as informative ones characterizing the sensitivity of the method and its effectiveness:

$A^{*}=\left\{\left|\Delta A\left(\varphi_{\min 1}\right)\right| / A_{\max 1},\left|\Delta A\left(\varphi_{\max 1}\right)\right| / A_{\max 1}\right.$, $\left.\left|\Delta A\left(\varphi_{\max 0}\right)\right| / A_{\max 0}\right\}$. 


\section{The scattering of ultrasonic waves when acoustic beam spot intersects defect boundary}

In this case the calculation of the summary scattered field is realized according to formula (1) but it is necessary to take into account the changing of the defect's boundary to intersect the boundary of the acoustical spot $S_{0}$.

The results of numerical calculations of the considered acoustic fields, including the characteristic dependences of amplitude parameters $|\Delta A| / A_{\max }$ on the geometry of the defect area, its position relative to the acoustic beam spot and the phase shift $\theta$ between the scattered UW on the defective and non-defective surface of the material interface are presented below. Figures 2 and 3 present the amplitude characteristics of the UW scattering field depending on the position of the defect area centre in the form of ellipse with different eccentricity, determined in the equatorial planes of the DD $\psi=0-\pi / 2$ for the indicated receiving angles at different values of the phase shift. Note that the indicated amplitude parameter $|\Delta A| / A_{\max }$, in fact, characterizes the sensitivity of the measurement method for various input-receive conditions of the UW. Figures 4 and 5 show data on the maximum sensitivity of the method, depending on the position of the defect area when its geometry and phase shift $\theta$ are changed. The data on the effect of a more complicated adhesion mechanism, characterized by a linear change in the value in the direction normal to the boundary of the defect area, which has the shape of a long strip, is illustrated in Figure 6.

When variant II is implemented (defect surface long strip), the phase shift, where is the coordinate of a point on the surface of the SD defect, counted in its plane normal to the amplitude characteristics of the UW scattering field depending on the position of the defect area centre in the form of ellipse with different eccentricity, determined in the equatorial planes of the $\mathrm{DD} \psi=0-\pi / 2$ for the receiving angles at different values of the phase shift. Note that the indicated amplitude parameter $|\Delta A| / A_{\max }$ in fact characterizes the sensitivity of the measurement method for various input-receive conditions of the UW. Figures 4 and 5 show data on the maximum sensitivity of the method depending on the position of the defect area when its radius and phase shift $\theta$ are changed. The data on the effect of a more complex material coupling mechanism characterized by a linear change in the value in the direction normal to the boundary of the defect area, which has the shape of a long strip, is illustrated in Figure 6.
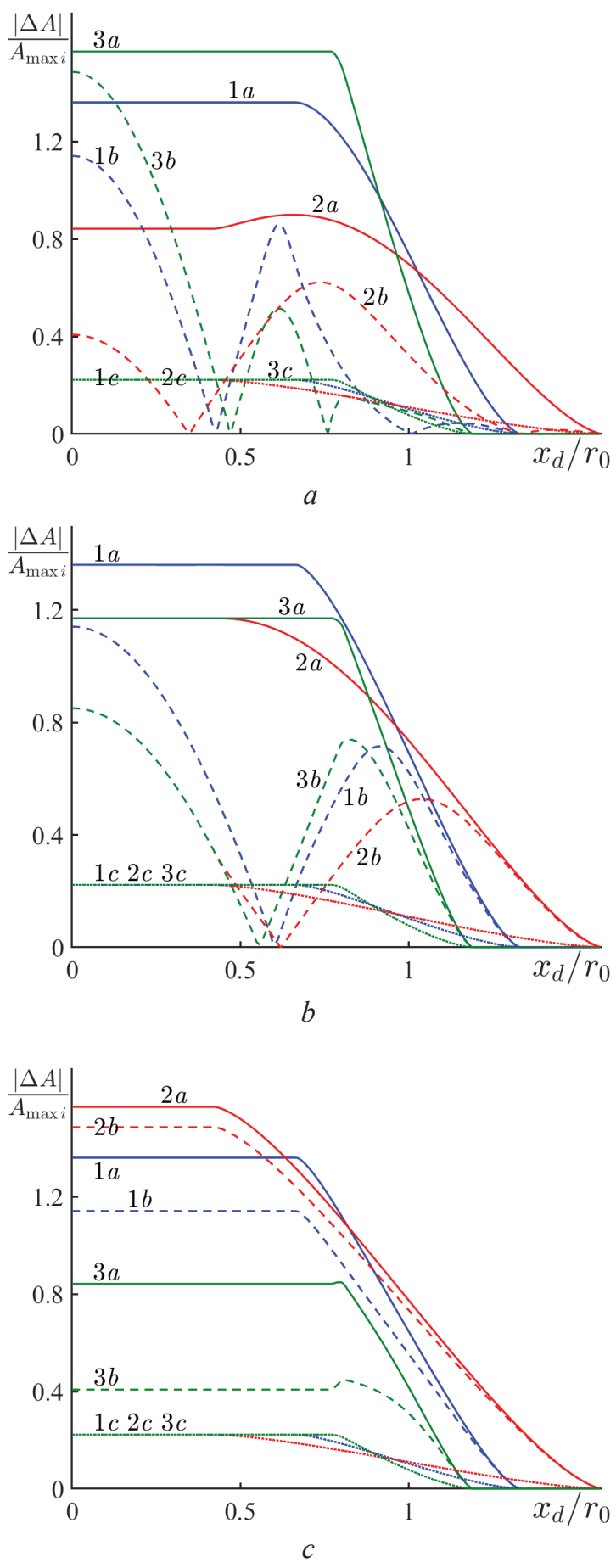

Figure 2-Amplitude characteristics of the ultrasonic scattering field vs the position of the defect area centre in the form of ellipse, determined for $\psi=0(a), \pi / 4(b)$, $\pi / 2(c)$ and different angles of wave reception $\varphi$ at phase shift $\theta=\pi$ : eccentricity of the ellipse $\varepsilon=1(1), 3(2)$, $1 / 3$ (3); angle of the UW reception $\varphi=\varphi_{\min 1}(a), \varphi_{\max 1}(b)$, $\varphi_{\max 0}(c) ; r_{0} / \lambda=5 ; S_{D} / S_{0}=1 / 9$ 

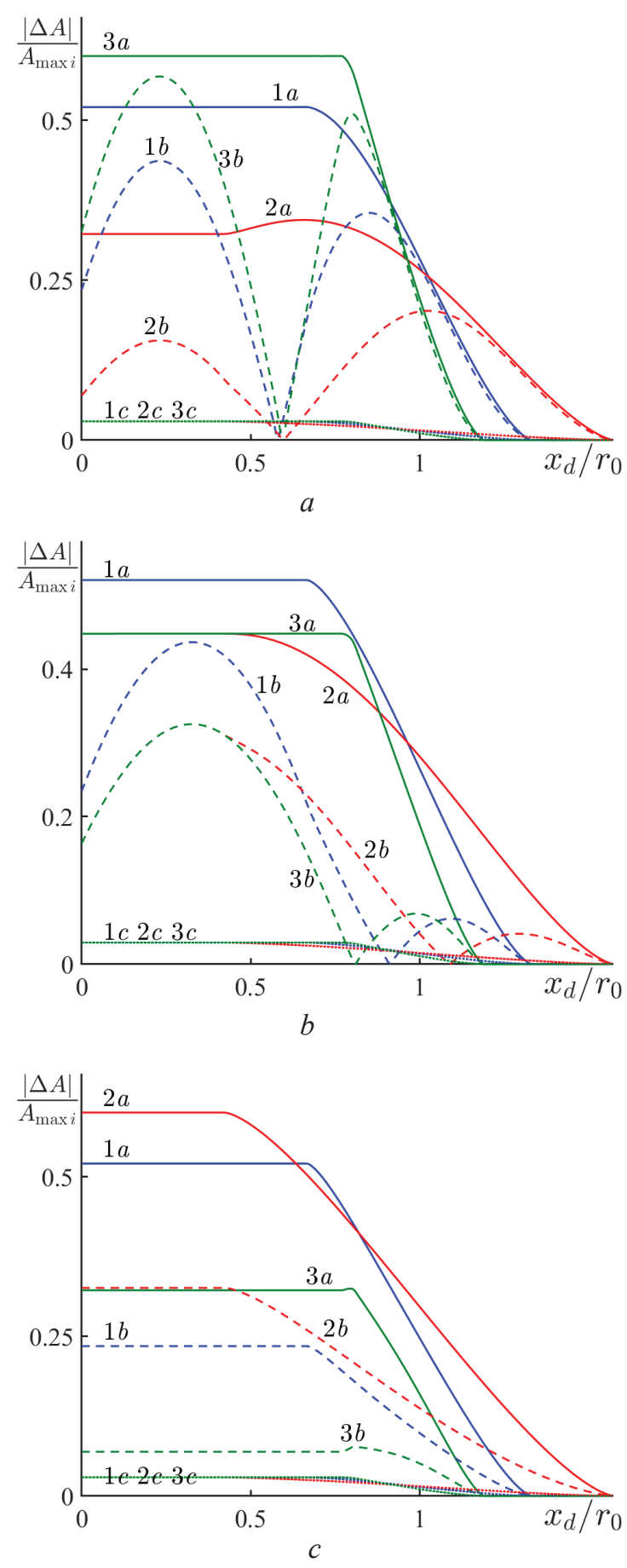

Figure 3-Amplitude characteristics of the ultrasonic scattering field vs the position of the defect area centre in the form of ellipse, determined for $\psi=0(a), \pi / 4(b)$, $\pi / 2(c)$ and different angles of wave reception $\varphi$ at the phase shift $\theta=\pi / 4$ : eccentricity of the ellipse $\varepsilon=1$ (1), 3 (2), 1/3 (3); angle of the UW reception $\varphi=\varphi_{\min 1}(a)$, $\varphi_{\max 1}(b), \varphi_{\max 0}(c) ; r_{0} / \lambda=5 ; S_{D} / S_{0}=1 / 9$

The presented results of theoretical analysis of the influence of geometrical parameters of the model defect area on the generated acoustic scattering field of UW at its relative crossing by the spot of the acoustic beam convincingly indicate the effectiveness of the suggested method of evaluation the adhesion quality of materials which consists in the application of a "non-mirror scheme" of UW radiation-receiving. Those, not only the angles of UW radiation and receiving but also the planes of incidence of the source and receiver of the ultrasonic probe may not coincide.
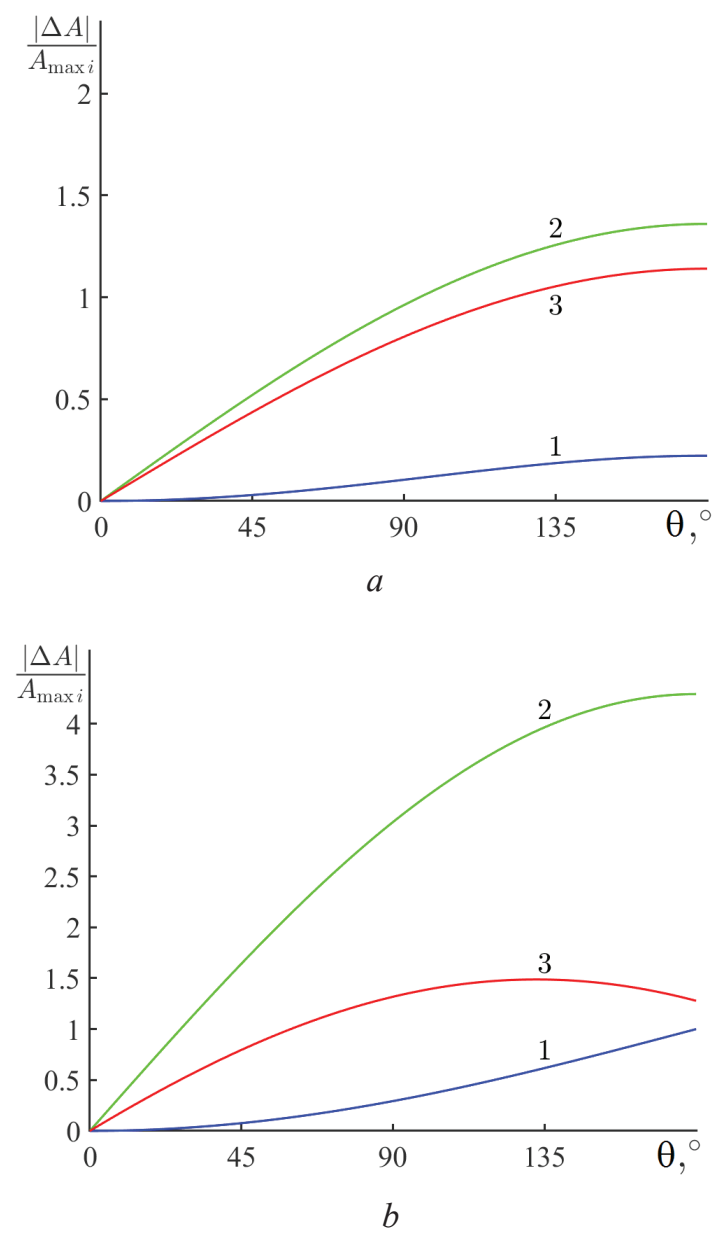

Figure 4 - Maximum variation of ultrasonic amplitude at displacement of acoustic beam spot relative to the centre of circular defect $(a)$ and half-plane boundary $(b)$ as a function of phase shift of waves scattered from the defect: angle of ultrasonic reception in equatorial plane $\psi=0$ : $\varphi=\varphi_{\max 0}(1), \varphi_{\min 1}(2), \varphi_{\max 1}(3), r_{0} / \lambda=5 ; S_{D} / S_{0}=1 / 9$

In case of orientation of the major axis of the ellipse a (or "elongation") of the defect along the $x$-axis $(\varepsilon=a / b>1)$ it is preferable to receive $\mathrm{UW}$ in the plane determined by equatorial angle $\psi \rightarrow \pi / 2$ for $\varphi \rightarrow\left\{\varphi_{\max 1}, \varphi_{\min }\right\}$. But if the major axis of the ellipse $a$ directed along the $y$-axis then the situation is the more preferable for ultrasonic receiving if $\psi \rightarrow 0$. A similar tendency is maintained when the 
phase shift between scattered waves in a varying range $(1 / 8-1) \pi$. The sensitivity of the suggested method can significantly (by more than order of magnitude) exceed the traditional "mirror" version of testing. (The latter is implemented for radiation-receiving) conditions at angles close to each other). As seen from figures $2-5$ the absolute value of $\delta_{A}=|\Delta A| / A_{\max 1}$ can be up to $\sim 10$ and more times. With decreasing the defect area $S_{D}$ and phase shift $\theta \sim \pi$ the value of amplitude $A$ mostly decreases irrespective of the equatorial angle. At the same time, at phase shift $\theta \sim \pi$ and $r / R>0.6$, the ambiguity of measurement can be observed if the ultrasonic receiving is performed when $\varphi \rightarrow \varphi_{\max 1}$ (Figure 5).
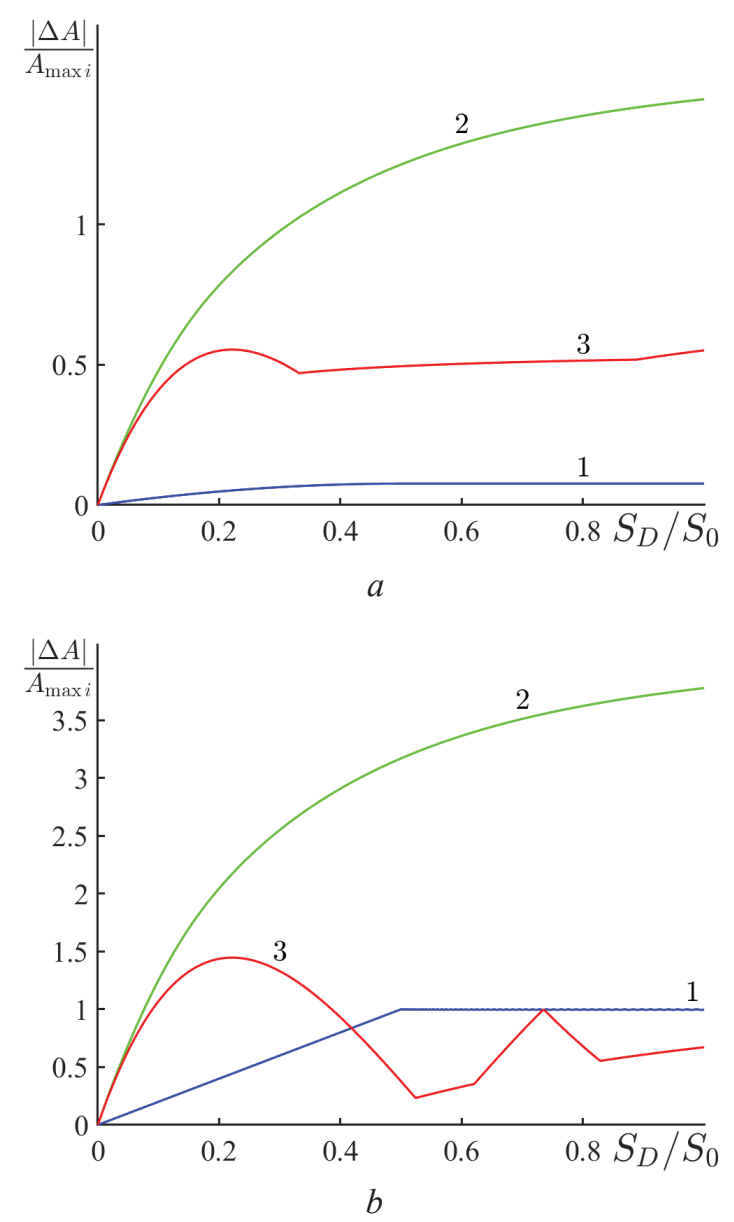

Figure 5 - Maximum signal change when the acoustic beam spot is displaced relative to the centre of a circular defect as a function of its radius and phase shift $\theta=\pi / 4(a)$; $\pi(b)$; angle of ultrasonic reception in the equatorial plane: $\varphi=\varphi_{\max 0}(1), \varphi_{\min 1}(2), \varphi_{\max 1}(3) ; r_{0} / \lambda=5$

It is noteworthy that in the case of defect modeling in the form of a strip with a linearly varying phase shift (Figure 6), which is typical for poorly detectable defects occurring in various material joining technologies, the maximum sensitivity is achieved exactly when ultrasonic scanning is received in the equatorial plane of the DD section $\psi=\pi / 2$ and azimuth angles close to $\varphi \rightarrow \varphi_{\min 1}$. Thus, in comparison with the mentioned classical method, the calculated sensitivity of the suggested method is almost $\sim 50$ times greater when the varying value of the phase shift between the waves scattered from the defect-free and defect material boundaries $\phi=\pi / 4$.
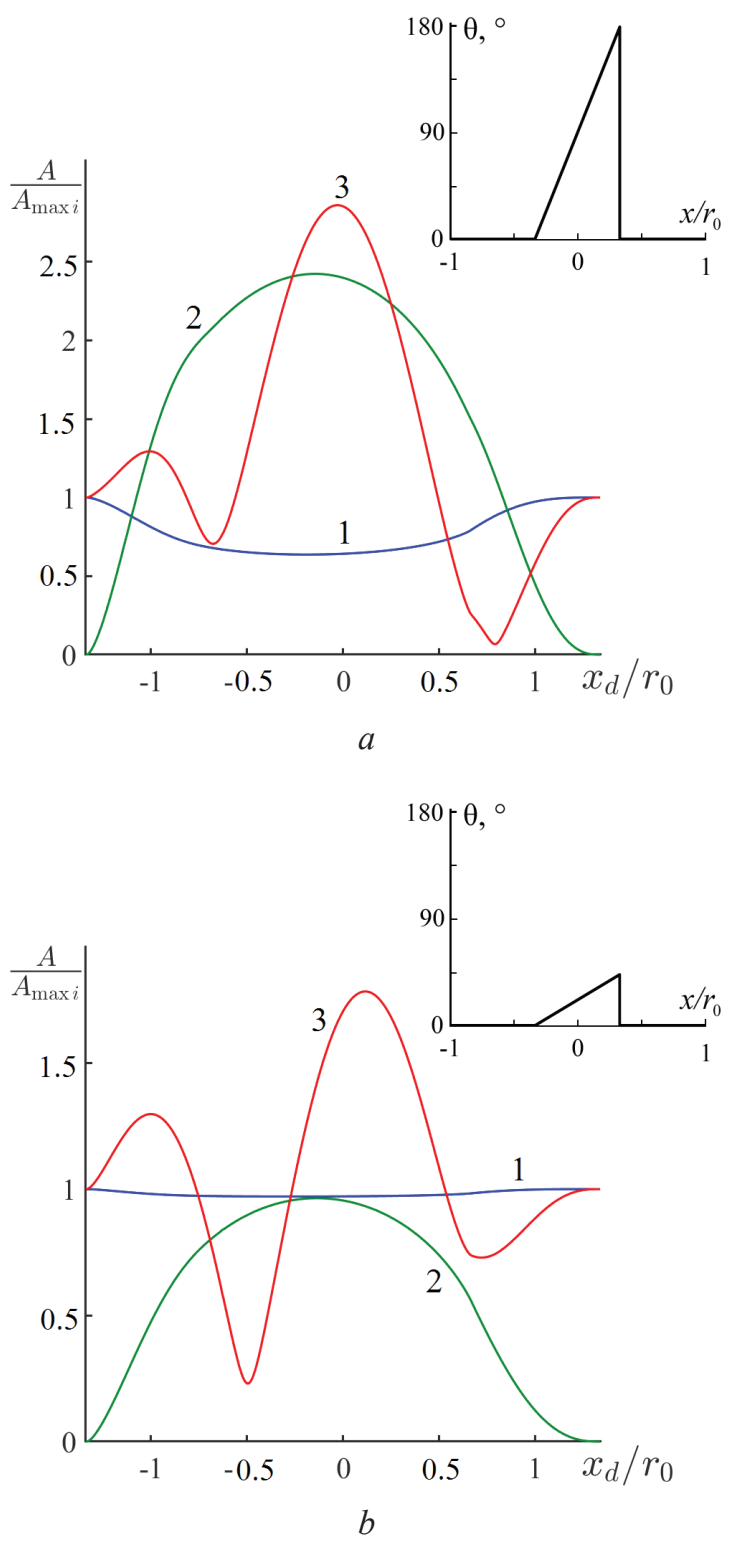

Figure 6 - Characteristic signal amplitude dependence of ultrasonic scattering field vs displacement of the acoustic beam spot centre relative to the defect area in the form of a long strip with a linear change in phase shift in the $x$ direction: $\max (\theta)=\pi(a) ; \pi / 4(b) ; \varphi=\varphi_{\max 0}(1) ; \varphi_{\min 1}(2)$; $\varphi_{\max 1}(3) ; r_{0} / \lambda=5$; defect width is of $b=2 / 3 r_{0}$ 
Thus, based on these calculations and theoretical analysis, the maximum sensitivity of the method is achieved both by optimizing the parameters of the acoustic channel in order to achieve the maximum, and, importantly, by receiving the scattered signal at the above characteristic angles of the primary DD diagram of the scattering field, including $\psi$ and $\varphi$. If we consider the diagnostic state of the adhesion quality of materials according to the scheme shown in Figure $1 b$, then in describing the acoustic path it is necessary to take into account the features of the ultrasonic traverse through the outer boundaries of the object, accompanied by energy loss and the shift of the acoustic beam due to refraction on the boundaries. For example, when the echo method used an acoustical signal passes twice only one external surface of the object I. With weak divergence of acoustic beams scattered from defective and defectfree surfaces in the layer of object II, the condition must be fulfilled:

$0.5 h f\left(n \cos \alpha C_{2}\right)>1, h / L<<1$,

where $L$ is the distance from the surface I of the object to the receiving point of UW.

In this case, as a result of refraction of the acoustic beam at the interface I the transverse size of the acoustic beam changes in $\cos \beta / \cos \alpha$ time. Finally, the scattering field formation process takes place exactly in the area I. If this condition is not met, then the scattered waves incident at different angles $\alpha_{i}$ at the interface I will undergo a change in amplitude due to the dependence $D_{21}=D_{21}\left(\alpha_{i}\right)$. As a more detailed analysis of this phenomenon shows, it will only affect some variation in the amplitude-angle characteristics of the scattering field which must be taken into account when designing the measurement technique and positioning the receiver probe with respect to the object surface.

\section{Conclusion}

A theoretical model for detection of poorly detectable adhesion defects based on optimization of apertures and phases of imaginary ultrasonic sources scattered by inhomogeneous boundary including defects as a long strip and ellipse with variable eccentricity (3-1/3), presence of discrete and linearly variable phase shift between waves scattered by defect and defect-free area is developed in axial approximation.
Evolution features of the scattering field structure, which are primary for the development of techniques to evaluate the adhesion of materials by the specified method, have been found. It is shown that with sufficiently small values the maximum sensitivity of the method is achieved in a dynamic way and receiving of scattered waves under the azimuthal angles corresponding to the first extremums of the directivity diagram of the scattering field of the reference signal (in the absence of defect).

In the case of numerical simulation of defects in the form of a band with a linearly changing phase shift, which is typical for weakly detectable defects, the maximum sensitivity of the method is achieved when receiving waves in the equatorial plane of the scattering field of directivity diagram section $\psi=\pi / 2$ and in the neighborhood of the azimuthal angle of minimum of the first order. It is shown that in comparison with traditional methods the sensitivity of control of poorly detectable defects in conditions when the phase shift between the waves reflected from the defect and non-defective surface is tens of degrees.

\section{Acknowledgments}

The work was supported by the Belarusian Republican Foundation for Fundamental Research of the Republic of Belarus, project No. 136.

\section{References}

1. Nondestructive Testing: Handbook: In 7 vols. Klyuev. Vol. 3. Moscow: Mashinostroenie, 2003, 864 p.

2. Kim H.-J., Song S.-J., Kim D.-Y., Kwon S.-D. Evaluation of thin coating layers using Rayleigh-like waves. Review of Progress in Quantitative Nondestructive Evaluation, Golden, Colorado, 22-27 July 2007, vol. 927, iss. 1, pp. 1066-1073.

DOI: $10.1063 / 1.2902550$

3. Adamyan Yu.E., Belov A.A., Greshnevikov K.V., Zhabko G.P., Kolodkin I.S., Krivosheev S.I., Magazinov S.G., Svechnikov E.L., Titkov V.V. Identification of transverse material boundaries in multilayer anthropogenic structures. Russian Journal of Nondestructive Testing, 2016, vol. 52, no. 4, pp. 185-196.

DOI: $10.1134 / \mathrm{S} 106183091604001 \mathrm{X}$

4. Murashov V.V., Sliussarev M.V. Detection of cracks in parts made of polymer composites and multilayer glued structures by low-frequency acoustic method. Defectoscopy, 2016, no. 6, pp. 27-34.

5. Santo J.B., Santon M.J. Ultrasonic interferometry for the evaluation of thickness and adhesion of thin layers. 
Abstracts of $4^{\text {th }}$ International Conference on NDT, China, Greece, 2007, p. 22.

6. Chambers J.K., Tucker J.R. Boundline analysis using swept-frequency ultrasonic spectroscopy. Insight, 1999, vol. 41, no. 3, pp. 151-155.

7. Kruger S.E., Lord M., Levesque D., Bakker A.J. Detection of kissing bond in extruded aluminum by laser-ultrasound. Review of Progress in Quantitative Nondestructive Evaluation, Golden, Colorado, 22-27 July 2007, vol. 975, iss. 1, pp. 279-285.

DOI: $10.1063 / 1.2902670$

8. Gurevich S.Yu., Petrov Yu.V., Golubev E.V., Shulginov A.A. EMA registration of ultrasonic Lamb waves excited by laser nanopulses. Russian Journal of Nondestructive Testing, 2013, vol. 49, no. 8, pp. 431-435.

DOI: $10.1134 / \mathrm{S} 1061830913080056$

9. Baev A.R., Asadchaya M.V. Part 1. Features of acoustic beam reflection from a surface with non-uniform boundary conditions. Part 1 . Theoretical analysis. Russian Journal of Nondestructive Testing, 2010, vol. 46, no. 8, pp. 3-17. DOI: 10.1134/S1061830910080012

10. Baev A.R., Levkovich N.V., Mayorov A.L., Asadchaya M.V. Rasseyanie uprugih voln neodnorodnoj granicej pri akusticheskom kontrole neraz"yomnyh soedinenij [Scattering of Elastic Waves by an Inhomogeneous Boundary in the Acoustic Testing of Permanent Joints]. Devices and Methods of Measurements, 2019, vol. 10, no. 4, pp. 360-372 (in Russian).

DOI: $10.21122 / 2220-9506-2019-10-4-360-372$ 